\title{
OS SOLOS COMO INDICADORES DAS RELAÇÕES ENTRE SEDIMENTOS CONTINENTAIS E MARINHOS NA PLANÍCIE COSTEIRA: RIO GUARATUBA (SP) $)^{(\mathbf{1})}$
}

\author{
M. ROSSI (2) \& J . P. QUEIROZ NETO(3)
}

\begin{abstract}
RESUMO
Foram estudadas duas toposseqüências na planície litorânea no rio Guaratuba (SP), definindo seqüência de evolução pedológica e de deposição/ acumulação, utilizando a análise macromorfológica de solos por meio de tradagens. A primeira seqüência ilustra a transformação de Espodossolo Ferrocárbico (Podzol) sobre sedimentos arenosos marinhos para Organossolo (solo orgânico), enquanto a outra mostra a relação entre Gleissolo Háplico (solo glei pouco húmico) sobre sedimentos continentais e Espodossolo Ferrocárbico (Podzol) em sedimentos areno-quartzosos marinhos. A sedimentação marinha é representada por feixes de restinga arenosos, com zonas embaciadas, propiciando o desenvolvimento de Espodossolos nas partes altas e Organossolos nas partes baixas. Morros isolados inferiores à planície funcionaram como antigas zonas de balizamento desses feixes, que li mitaram o sistema deposicional continental, definindo o material marinho como anterior ao continental, onde ocorreu um encaixamento da drenagem próximo ao contato.
\end{abstract}

Termos de indexação: gênese, toposseqüência, Serra do Mar, Gleissolo, Espodossolo, Organossolo.

SUMMARY: SOILS AS INDICATORS OF THE RELATIONSHIPS BETWEEN CONTINENTAL AND MARINE SEDIMENTS ON THE COASTAL PLAIN : RIO GUARATUBA (SP)

Two toposequences on the coastal plain of Rio Guaratuba (SP) were studied to define the pedological and deposition/storage evolution by means of macromorphological soil

(1) Parte de Tese de Doutorado do primeiro autor, apresentada no II Simpósio Nacional de Geomorfologia em Florianópolis (SC). Recebido para publicação em abril de 2000 e aprovado em outubro de 2000.

(2) Pesquisador Científico do Instituto Agronômico de Campinas - IAC. Caixa Postal 28, CEP 13001-970 Campinas (SP). Email rossi@barao.iac.br;

(3) Professor do Departamento de Geografia, Faculdade de Filosofia, Letras e Ciências Humanas - FFLCH-USP. Caixa Postal 2350, CEP 01060-970 São Paulo (SP). E-mail: laboped@edu.usp.br. 


\begin{abstract}
analysis. Thefirst sequence shows thechange of a Podzol into organic soil on marinesandy sediments, whereas the second one shows the relationship of a Gley Soil on continental sediments with a Podzol soil on marinesedi ments. Marinesedimentation was found to form sandbanks with internal depression zones, which al lowed the devel opment of a Podzol in the highlands and Organosol on the lowlands. I solated hills of the anterior coastline have acted as physical barriers to themarinesandbanks, thus limiting continental sedimentation; the drainage system was cut along the contact zone, suggesting that the marine deposits have preceded the continental deposits.
\end{abstract}

Index terms: genesis, toposequence, Serra do Mar, gl eissolo, espodossolo, organossolo.

\section{NTRODUÇÃO}

A planície litorânea de Guaratuba representa a parte final da bacia do rio Guaratuba, limitando-se a sudoeste com o chamado litoral santista, onde as planícies passam a ser mais largas e extensas, e a nordeste com o litoral de São Sebastião, onde as escarpas da Serra do Mar acham-se próximas do mar e as praias têm dimensões mais reduzidas.

A costa oriental brasileira nolitoral norte deSão Paulo esul do Rio deJ aneiroé definida por escarpas cristalinas assimétricas e elevados desníveis, resultantes do tectonismo recente, onde o mar atinge diretamente o Escudo Atlântico. Esse tectonismo e a erosão subseqüente propiciaram a formação de uma margem costeira com costões salientes e reentrâncias, onde a sedimentação marinha construiu cordões de restinga e praias, que configuram a baixada litorânea (RADAMBRASIL, 1983). As escarpas, parte do planalto e as planícies compõem o Parque Estadual da Serra do Mar, que inclui a bacia do Guaratuba, entre as coordenadas $45^{\circ} 47^{\prime} 43^{\prime \prime}$ e $45^{\circ} 55^{\prime} 56^{\prime \prime}$ de longitude oeste e $23^{\circ} 38^{\prime} 37^{\prime \prime}$ e 2346'12" de latitude sul (Figura 1 ).

A planícielitorânea do Rio Guaratuba caracterizase por sedimentos quaternários fluviais, marinhos ou fluvio-lacustres, com vegetação pi oneira herbácea a arbórea, em solos submetidos, via de regra, ao hidromorfismo. A vegetação dominante é a Mata Atlântica, que apresenta diferenças, podendo ser subdividida em florestas paludosas, floresta da restinga e mangues, dentre outras. Apresenta clima tropical úmido, caracterizando-se por elevadas precipitações, mais de 2.000 mm por ano.

Os sol os dominantes, segundo BRASI L (1960), são os Podzóis e sol os hidromórficos, influenciados pelo lençol d'água, enquanto RADAMBRASIL (1983) só mencionou a presença de Podzol Hidromórfico sobre sedimentos marinhos arenosos eareno-argil osos. Na Baixada Santista, Queiroz Neto \& Küpper (1965) apontaram a presença, em áreas arenosas, de feixes de restinga, a associação Podzol Hidromórfico nas partes altas e solos orgânicos nas depressões com saturação hídrica e carência de oxigênio que criam um ambiente redutor, onde a matéria orgânica acumula-se pela lenta humificação; identificaram, ainda, sol os orgânicos em depressões mais amplas e Gleis Pouco Húmicos e aluviões nos sedimentos continentais.

Em trabalho recente, Oliveira et al. (1999) indicaram a presença, nessa parte litorânea, de Espodossol o F errocárbico Órtico com A proeminente e moderado, associado ao N eossolo Quartzarênico Órtico distrófico A moderado e, em pequenas áreas, - Gleissolo Sálico Órtico textura média, associado ao Neossolo Quartzarênico Hidromórfico salino A moderado.

$\mathrm{Na}$ parte sudoeste da planície costeira do Guaratuba, foram estudadas duas toposseqüências, com o objetivo de definir as relações entre os solos, as formas de relevo e o material de origem.

\section{MATERIAL E MÉTODOS}

Estabel eceram-seduas toposseqüências em áreas amostrais da planície litorânea da bacia do Guaratuba, cujo mapeamento de sol os foi realizado por Rossi \& Queiroz Neto (1999). A escolha das toposseqüências inspirou-se em Boulet (1988a,b), procurando mostrar a distribuição dos solos, do rel evo e da geol ogia da área. Com o auxílio detopofil, trena e clinômetro, construiu-se em campo, metro a metro, a topografia local, que, posteriormente, foi situada em um gráfico (perfil). Os solos foram identificados nessa linha topográfica estabelecida anteriormente, a partir de prospecções com trado, descrevendo-se detalhadamente os atributos pedológicos, suas modificações e definindo-se as transições entre os solos.

Foram descritos e coletados solos de 14 pontos, destacando-se os mais representativos da evolução pedológica encontrada. Na toposseqüência 1, os solos são simbolizados por T1 e, na toposseqüência 2, por T2. Nessas tradagens, foram observadas a textura, a cor, a espessura dos horizontes ea posição do lençol freático, seguindo Lemos \& Santos (1996). 


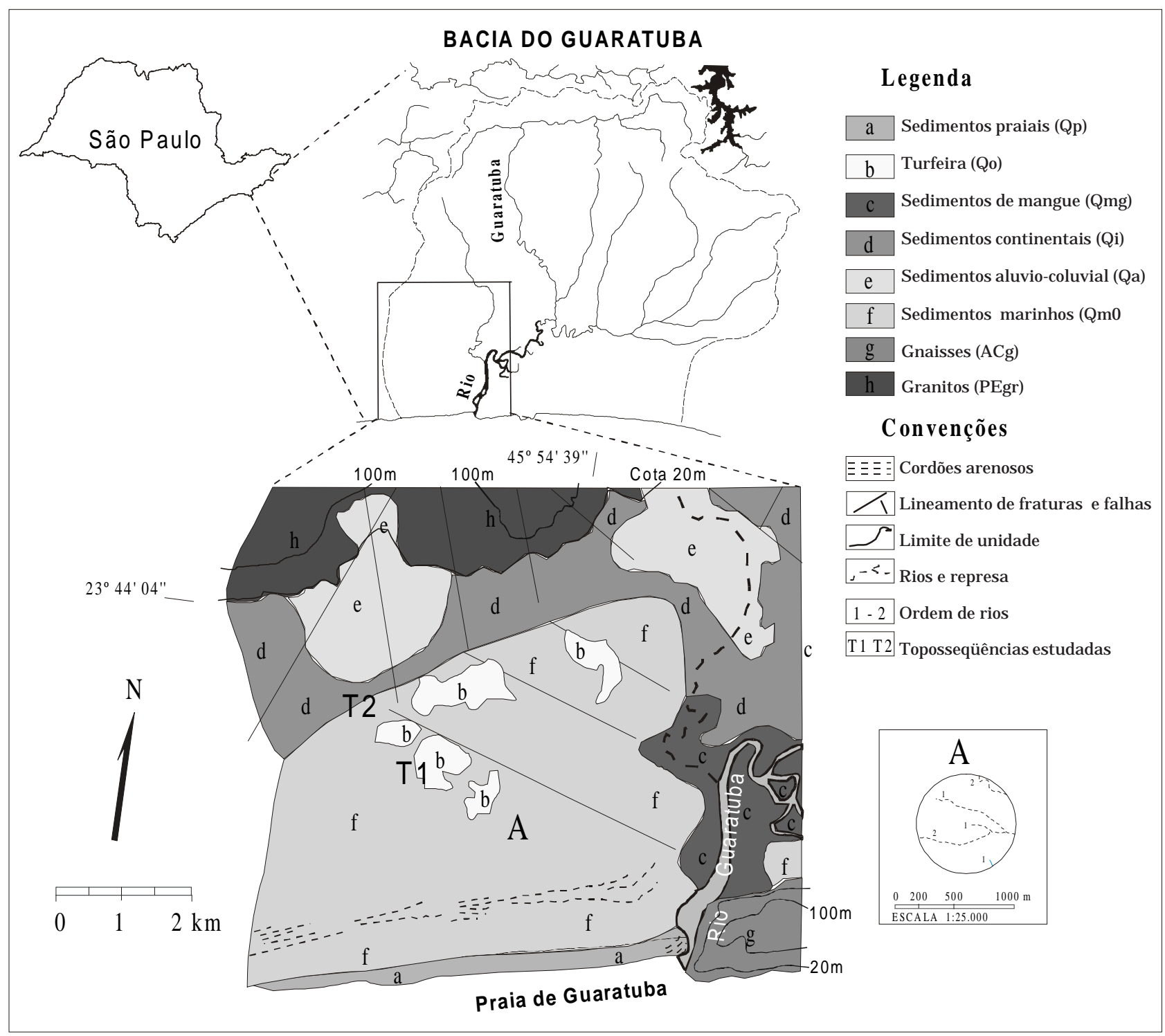

Figura 1. Mapa de localização e da geologia da Bacia do Guaratuba, São Paulo. Fonte Rossi \& Queiroz Neto $(1996 a, b)$.

Os solos foram identificados e classificados de acordo com Camargo et al. (1987) com adequação ao sistema brasileiro de classificação de solos, EMBRAPA (1999).

Nos pontos de prospecção, coletaram-se as amostras de solo das diferentes camadas ehorizontes para posterior análise laboratorial: análises físicas (granulometria: areias, silte e argila) e químicas (cátions trocáveis- $\mathrm{Ca}^{2+}, \mathrm{Mg}^{2+}, \mathrm{K}^{+}, \mathrm{Na}^{+}$; acidez- $\mathrm{Al}^{3+}$, $\mathrm{H}$; pH em água eKCl; matéria orgânica), utilizandose como índices: Soma de bases (S) $=\mathrm{Ca}+\mathrm{Mg}+\mathrm{K}+$ $\mathrm{Na}$; capacidade de troca catiônica $(\mathrm{T})=\mathrm{S}+\mathrm{Al}+\mathrm{H}$; saturação por bases $(\mathrm{V} \%)=\mathrm{S} / \mathrm{T}$ 100; saturação por $\mathrm{Al}(\mathrm{M} \%)=100 \mathrm{Al} /(\mathrm{S}+\mathrm{Al})$; seguindo as normas estabelecidas por Camargo et al. (1986).

\section{RESULTADOS E DISCUSSÃO}

O mapa geológico(Figura 1) mostra a distribuição dos sedimentos marinhos e flúvio-lacustres continentais na porção oriental da planície do Guaratuba. Percebem-se não só a Iarga faixa de cordões arenosos de restinga, acompanhando, de forma geral, a linha de costa atual, mas também a sua retaguarda até o sopé da encosta da Serra, uma faixa mais estreita de depósitos continentais que, a leste, acompanham o curso do rio Guaratuba em direção ao mar até encostarem no morro isol ado que fecha essa parcela da planície. Sobre a deposição continental, fluvio-lacustree na desembocadura dos afluentes do rio principal, ocorrem sedimentos mais 
recentes, aluvio-coluviais. A área apresenta, ainda, diversas formações deter raços marinhos com vários níveis de altitude, cordões recentes $(2 \mathrm{~m})$, terraços marinhos baixos (2-5 $\mathrm{m}$ ) e terraços marinhos altos (5-7 m).

As sensíveis diferenças entre sedimentos continentais e marinhos dizem respeito: à textura, franco-argilo-siltosa, franco-argil osa, franco e argila dos primeiros, que contêm micas do tipo alteração de biotita por perda de ferro, e essencialmente arenosas do segundo (Figura 2); ao microrelevo, praticamente plano no primeiro caso e fortemente microondulado, correspondendo à seqüência de antigos cordões de restinga, no segundo caso; à posição do lençol freático, aflorante ou subaflorante sobre os depósitos continentais eapenas nas partes baixas entre os cordões arenosos dos terraços marinhos.

Nessa área, foram estudadas duas toposseqüências: a de número 1, que corresponde a um exemplo de sucessão de solos sobre os cordões de origem marinha, e a toposseqüência 2 , que mostra um exemplo da zona de contato entre os dois tipos de sedimentos (Figura 2).
A topossequência 1 (F igura 2 ) sobre cordãoarenoso de um feixe de restinga apresenta, na parte alta, um perfil deEspodossol oFerrocárbico HiperespessoálicoESu (Podzol), com horizonte A mineral com el evado teor de matéria orgânica, escuro (7,5YR 3/3), com raízes abundantes, sobre um horizonte $\mathrm{E}$ branco (10YR 7/1) de areia lavada e espessura de cerca de $250 \mathrm{~cm}$, passando rapidamente a um Bsh arenoso, escuro, de acumulação de matéria orgânica e ferro. O Espodossolo (Podzol ) ocupa toda a vertentedo cor dão até quase sua base, passando a Organossolo Mésico Sáprico térrico distrófico-OYs (sol o orgâni co) nofundo do espaço intercordões onde o lençol freático aflora.

O Espodossolo (Podzol) (Quadro 1) apresenta, no horizonte superficial, $\mathrm{pH}$ ácido $\mathrm{em}_{2} \mathrm{O}$ (cerca de 4,5), com teores baixos de soma de bases e saturação por alumínio baixa, tornando-o distrófico. No Organossolo (sol o orgânico), o pH em $\mathrm{H}_{2} \mathrm{O} 4,1$ eem KCl 2,7 aponta caráter muito ácido com delta $\mathrm{pH}$, indicando elevada partici pação da matéria orgânica na geração de carga. A soma de bases e a capacidade de troca de cátions são relativamente el evadas, conforme os teores el evados de matéria orgânica. Esses valores elevados de bases no horizonte superficial do Organossolo (solo orgânico) são atribuídos aos

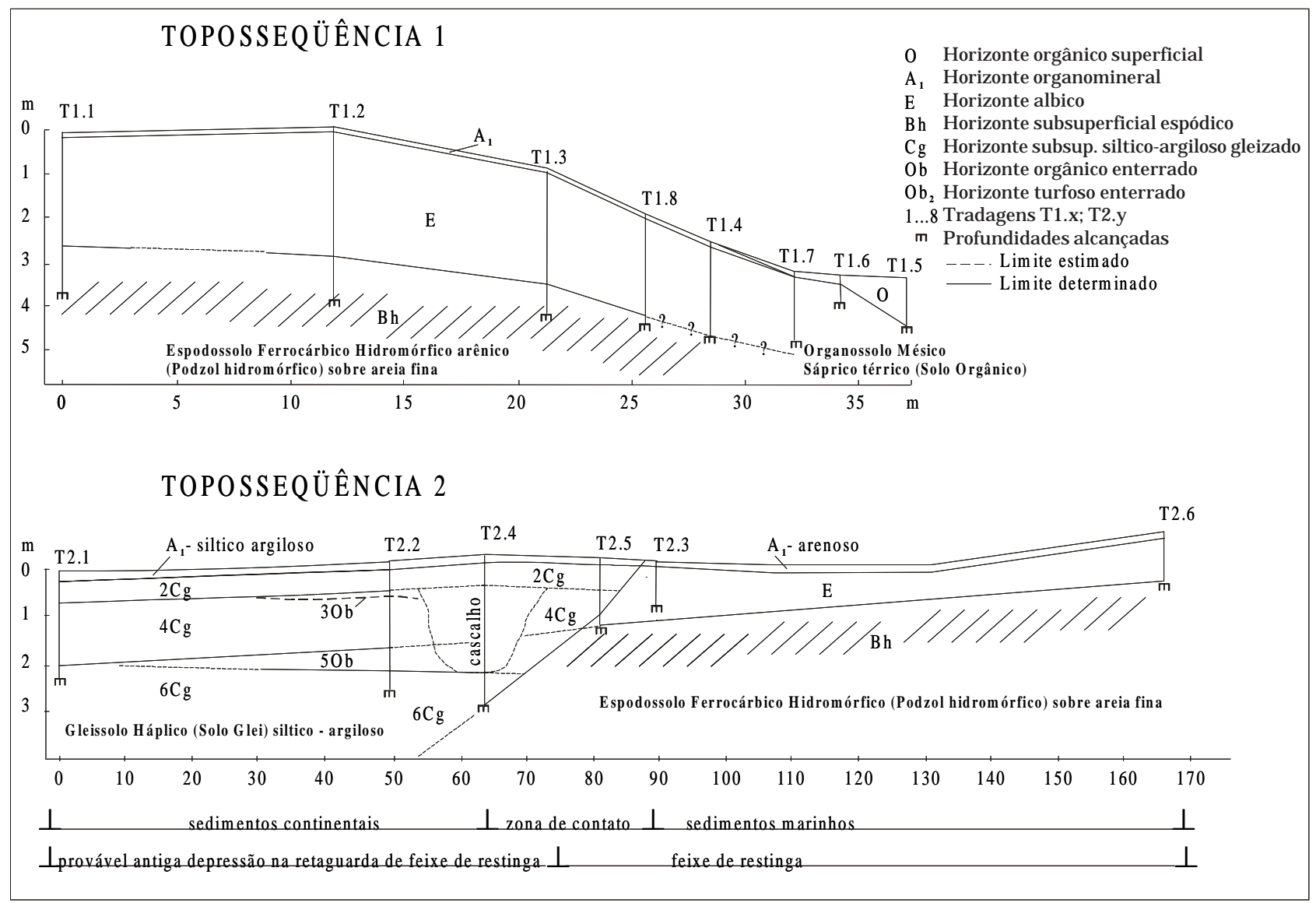

Figura 2. Toposseqüências 1 e 2 representando a passagem de Gleissolo (solo glei) para Organossolo (solo orgânico) e Gleissolo (solo glei) para espodossolo (Podzol), respectivamente. 
nutrientes presos à ciclagem da vegetação, com baixa mineralização por deficiência de $\mathrm{O}_{2}$.

Os teores de carbono orgânico, entre 0 e $45 \mathrm{~cm}$ de profundidade no Organossolo $\left(225 \mathrm{~g} \mathrm{~kg}^{-1}\right)$, junto como material arenoso, apresentam sensação ao tato sedosa, col oração escura (2,5YR 2/1) e, em superfície ainda, material fibroso. Esseteor éresponsável pelos valores de soma de bases $\left(8,10 \mathrm{cmol}_{\mathrm{c}} \mathrm{kg}^{-1}\right)$ e capacidade de troca de cátions total $\left(67 \mathrm{cmol}_{\mathrm{C}} \mathrm{kg}^{-1}\right)$, além de propiciar, por meio da atuação dos ácidos orgânicos, o aumento da acidez e a el evada retenção do alumínio $\left(4,8 \mathrm{cmol}_{\mathrm{C}} \mathrm{kg}^{-1}\right)$ e hidrogênio trocáveis $\left(54,5 \mathrm{cmol}_{\mathrm{c}} \mathrm{kg}^{-1}\right)$.

A toposseqüência 2 (Figura 2) é transversal ao limite entre os sedimentos marinhos arenosos e os continentais franco-argilo-siltosos. Apresenta perfis de Espodossolo Ferrocárbico Hidromórfico arênico distrófico (Podzol) sobre os primeiros, similares aos da seqüência anterior, porém com Bsh a menores profundidades, e de Gleissolo Háplico Tb distrófico típico álico (Glei) sobre os sedimentos continentais. A sucessão de horizontes é complexa, como mostra o ponto 2 (T2.2): um horizonte superficial A, mineral com elevadoteor de carbono orgânico, escuro (5YR 2/ 2), passa progressivamente a um $2 \mathrm{Cg}$, gleisado com col oração clara (10Y 6/2) e mosqueamento (10YR 4/ 6); a cerca de $40 \mathrm{~cm}$ de profundidade, aparece um primeiro horizonte escurecido de matéria orgânica (7,5YR 3/2) 30b, de $10 \mathrm{~cm}$ não-contínuo, sobre o horizonte $4 \mathrm{Cg}$, esverdeado (5GY 5/1) e mosqueado (7,5Y 4/2); entre 180 e $240 \mathrm{~cm}$, observa-se um horizonte negro (10R 2/1), turfoso $50 \mathrm{~b}$, que tende a desaparecer na direção do ponto 1, e abaixo, outro 6 Cg gleisado e esverdeado (5Y 4/2), contínuo.

O horizonte superficial A e o subsuperficial $2 \mathrm{Cg}$ apresentam continuidade lateral em toda a extensão observada $(90 \mathrm{~m})$, sendo seguidos por diversos horizontes franco-argilo-siltosos com atributos de cor (mosqueamento e cores neutras), indicativos de hidromorfia, intercalados por camadas descontínuas de material orgânico. Próximo ao contato com a formação marinha, abaixo do $2 \mathrm{Cg}$, apareceuma bolsa de cascalho com matriz arenosa, que corta o horizonte turfoso 50b, porém não o 6Cg. Além disso, os horizontes orgânicos 30 b e 50 b não se estendem lateralmente, não atingindo o ponto 1 . O retrabal hamento do material continental sobreposto aos depósitos marinhos ocorre de forma abrupta.

O E spodossolo (Podzol) apresenta (Quadro 2), em superfície, pH ácido $(4,4)$ em $\mathrm{H}_{2} \mathrm{O}$, soma de bases baixa $\left(1,04 \mathrm{cmol}_{\mathrm{c}} \mathrm{kg}^{-1}\right)$ e $\mathrm{H}^{+}$e $\mathrm{Al}^{3+}$ el evados, compatíveis com o pH. O teor de carbono orgânico, em torno de $12 \mathrm{~g} \mathrm{~kg}^{-1}$, éresponsável pela capaci dade de troca de bases em torno de $10 \mathrm{cmol}_{\mathrm{C}} \mathrm{kg}^{-1}$, por ser o material composto basicamente por areias que pouco contribuem para o valor $\mathrm{T}$. A saturação por alumínio (30\%) não é considerada alta, tendo o solo, assim, apenas caráter distrófico, como ocorre com o horizonte diagnóstico subsuperficial Bhs.

O Gleissolo (Glei) apresenta quantidade grande de mica em todo o perfil. O quadro 2 apresenta os dados analíticos dessa seqüência e mostra que os solos são álicos, com el evados teores de saturação por alumínio, enquanto a soma de bases é baixa, tendo muitas vezes certa contribuição do sódio. Os teores de carbono orgânico alcançam valores altos mesmo em profundidade, o que comprova a presença de diversas fases de acumulação.

Assim, esses solos relacionam-se com o tipo de material onde se desenvolvem: sobre os sedimentos arenosos de origem marinha, encontram-se Espodossolos (Podzóis) e, nos cordões dos feixes de restinga, uma sucessão Espodossolo (Podzol)/ Organossol o, tal como Queiroz N eto \& Küpper (1965) haviam assinalado na Baixada Santista e Boulet $(1988 a, b)$ na Guiana F rancesa; sobre os sedimentos continentais, encontram-se Gleissolos (Gleis), de textura franco-argilo-siltosa com horizontes orgânicos enterrados e uma bolsa de seixos rolados de natureza fluvial.

O clima úmidoequente permitiu o desenvolvimento devegetaçãoflorestal comabundantefornecimento

\section{Quadro 1. Resultados analíticos de perfis da toposseqüência 1 Espodossolo/Organossolo (Podzol/solo orgânico) na planície Litorânea}

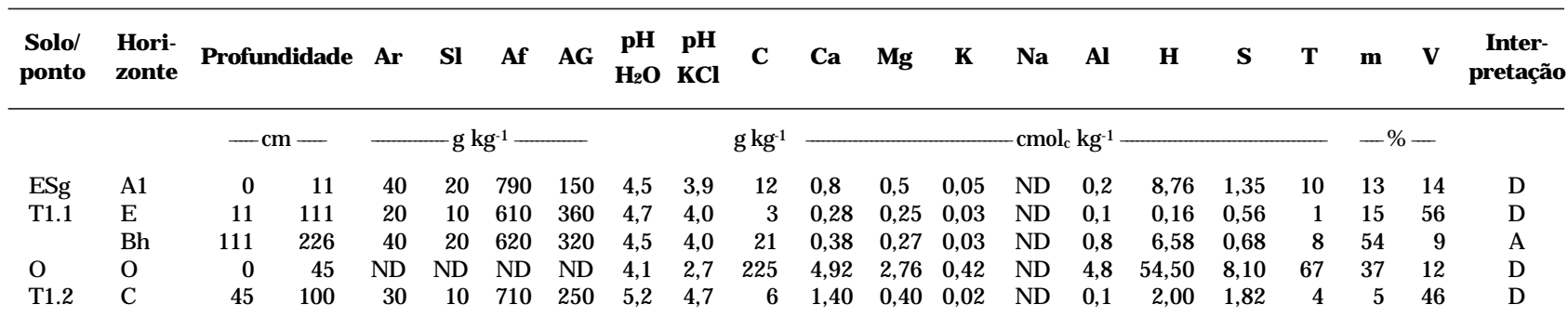

Ponto = número do ponto amostrado; Ar = argila; SI = silte; Af = areia fina; AG = areia grossa; C = carbono orgânico; Ca = cálcio; $\mathrm{Mg}=$ magnésio; $\mathrm{K}$ = potássio; $\mathrm{Na}=$ sódio; $\mathrm{Al}=$ alumínio; $\mathrm{H}$ = hidrogênio; $\mathrm{S}=$ soma de bases; $\mathrm{T}=$ capacidade de troca de cátions; $\mathrm{m} \%$ = saturação por alumínio; $\mathrm{V} \%=$ saturação por bases; interpretação dos dados analíticos; $\mathrm{A}=$ álico $(\mathrm{M} \%>50$ e $\mathrm{Al}>0,3)$; $\mathrm{D}=$ distrófico $(\mathrm{V} \%<50) ; \mathrm{E}=$ eutrófico $(\mathrm{V} \%>50$ e $\mathrm{S}>1,5)$. 


\section{Quadro 2. Resultados analíticos dos perfis da toposseqüência 2 espodossolo/gleissolo (podzol/glei pouco húmico) na planície Litorânea}

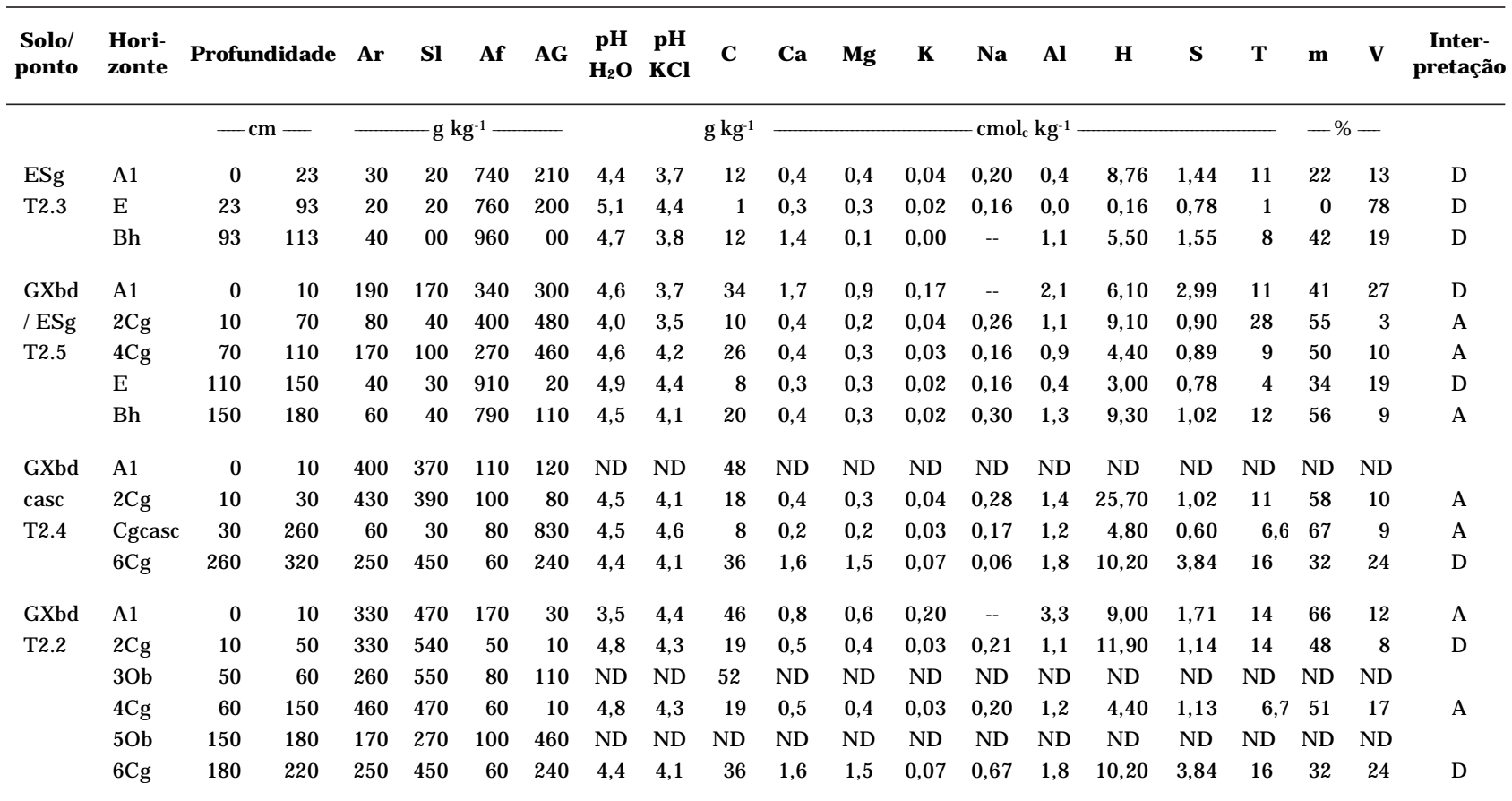

Ponto = número do ponto amostrado; $\mathrm{Ar}=$ argila; $\mathrm{SI}=$ silte; $\mathrm{Af}=$ areia fina; $\mathrm{AG}=$ areia grossa; $\mathrm{C}=$ carbono orgânico; Ca = cál cio; $\mathrm{Mg}=$ magnésio; $\mathrm{K}$ = potássio; $\mathrm{Na}=$ sódio; $\mathrm{Al}=$ alumínio; $\mathrm{H}$ = hidrogênio; $\mathrm{S}=$ soma de bases; $\mathrm{T}=$ capacidade de troca de cátions; $\mathrm{m} \%$ = saturação por alumínio; $\mathrm{V} \%=$ saturação por bases; interpretação dos dados analíticos; $\mathrm{A}=$ álico $(\mathrm{M} \%>50$ e $\mathrm{Al}>0,3)$; $\mathrm{D}=$ distrófico $(\mathrm{V} \%<50) ; \mathrm{E}=$ eutrófico $(\mathrm{V} \%>50$ e $\mathrm{S}>1,5)$.

de matéria orgânica ácida sobre o material arenoso muito poroso dos cordões e feixes de restinga; partes mais ativas das substâncias húmicas complexam o ferro e alumínio, migrando em profundidade, e preci pitando na zona deflutuação do lençol freático, originando os horizontes Bh/Bhs dos Podzóis.

$N$ as partes baixas entre os cordões, onde o lençol aflora, a matéria orgânica evolui muito lentamente em meio redutor, acumulando-se e originando Organossol os e eventualmente turfeiras.

Por outro lado, em diversos pontos da área pesquisada, foram observados, em profundidades diferentes, acumulações de compostos humo-férricos (níveis de Bhs), indicando diferentes momentos (períodos) de evolução, relacionados com outros níveis diferentes de lençol freático. Algumas dessas acumulações apresentam-se endurecidas (ortstein) em extensas e contínuas áreas, como nas proximidades da toposseqüência 1 , a cerca de $4 \mathrm{~m}$ de profundidade. Representariam períodos de intensa migração e preci pitação de complexos humoférricos, processos mais intensos de podzolisação e, ou, de estabilidade climática e de nível do mar.

Os morros isolados que ocorrem na planície litorânea a leste e os antigos costões a oeste, fora da área representada na figura 1, funcionaram como âncoras para a amarração dos antigos feixes de restinga. Na retaguarda destes, amplos espaços lagunares foram progressivamente preenchidos por sedimentos trazidos pel os rios que aí desembocam. A toposseqüência 2 mostra a posição de um antigo canal fluvial com cascal hos quase no limite entre os depósitos continentais e os marinhos. Além disso, percebe-se também a presença de dois níveis de material orgânico enterrado, o mais profundo, francamente turfoso.

É possível estabelecer uma seqüência de eventos da deposição continental: na base, a presença de sedimento fluvio-lacustre, franca $(6 \mathrm{Cg})$; acima, o horizonte turfoso enterrado (5Ob) indica período de certa estabilidade, sob forte hidromorfia (lençol permanentemente aflorante) que permitiu a acumulação de matéria orgânica em ambiente francamente redutor. A seguir, vol ta a se processar o assoreamento fluvio-lacustre $(4 \mathrm{Cg})$ que termina com nova fase de estabilidade e formação de horizonte orgâni co pouco espesso (3Ob). Condi ções de corrente fluvial com grande competência provocam o ental hamento do conjunto e a deposição dos seixos a partir da base do horizonte $4 \mathrm{Cg}$, quando retornam condições fluvio-lacustres mais tranqüilas (deposi ção 2Cg) e estabilização, ocorrendo a formação do solo atual com perfil O/A/Cg. 
O ponto T2.5, por outrolado, mostra o Gleissolo com horizonteA franco-arenoso sobre, sucessivamente, um horizonte glei mais arenoso $(2 \mathrm{Cg})$ e outro com maiores teores de silte e argila (4Cg), superpostos a um horizonte $\mathrm{E}$ ál bico de areia lavada e Bhs escuro (acúmulo de matéria orgânica) do Espodossolo (Podzol). A granulometria, além disso, mostra claramente a superposição entre sedimento continental/areias marinhas. Na partesuperficial $(A$, $2 \mathrm{Cg}$ e $4 \mathrm{Cg}$ ), a areia fina oscila entre 270 e $400 \mathrm{~g} \mathrm{~kg}^{-1}$, enquanto abaixo, $\mathrm{E}$ e Bh são, respectivamente, de 910 e $790 \mathrm{~g} \mathrm{~kg}^{-1}$, valores equivalentes aos do Espodossolo (Podzol) (T2.3) do qual sãooprolongamento: também os valores de argila e silte são muito mais el evados nos horizontes superiores, equival entes aos do Espodossolo (Podzol) nos horizontes inferiores.

O horizontesuperficial do T2.5 apresenta maiores teores de matéria orgânica (34 a $48 \mathrm{~g} \mathrm{~kg}^{-1}$ ) do que os perfis de Espodossol os (Podzóis) (12 $\mathrm{g} \mathrm{kg}^{-1}$ ) típicos, maior acidez $(\mathrm{pH}=3,7)$ e saturação por alumínio mais el evada. Com relaçãoao horizontesubsuperficial Bhs, este comporta-se como o Espodossolo (Podzol) imediatamenteaolado (ponto T2.3). Essas diferenças podem ser atribuídas a três motivos: acúmulo de material vegetal, hidromorfia em superfície e teor de argila maior, nos Gleissolos.

A presença dos sedimentos franco-argilo-siltosos, cujos materiais provêm das escarpas da Serra e do planalto, testemunha oassoreamento quase contínuo da antiga depressãolagunar, localmenteinterrompido por um momento de entalhamento fluvial. A presença de micas, de plaquetas milimétricas e douradas, observadas no campo nesses sedimentos, testemunharia a ocorrência de materiais não muito alterados nas áreas fontes. Ainda atualmente, os solos das escarpas contêm, com freqüência, esses minerais, não sendo a presença deles, por si só, indicadora de condições climáticas especiais.

A configuração do contato entre os sedimentos arenosos do feixederestinga eos franco-argilo-siltosos continentais, representada na toposseqüência 2 , mostra a anterioridade dos primeiros sobre os segundos.

A formação do horizonte Bhs estaria condicionada a uma zona de oscilação do lençol freático que, na ocasião, estaria quase 2 m abaixo do nível atual, que aflora ou subaflora nesse contato.

Restaria identificar a relação entre esse Bhs e o horizonte turfoso $50 \mathrm{~b}$ que, como indica a figura 2 , encontram-se em profundidades similares: isso seria indicador da formaçãocontemporânea desses horizontes, conseqüentemente, a um nível de mar mais baixo.

Geneticamente, pode-se dizer que, para a evolução e formação dos Espodossolos (Podzóis) dessa planície, os princi pais agentes atuantes são a natureza arenosa do substrato, o excedente hídrico e a temperatura elevada durante a maior parte do ano, que promovem a formação de ácidos orgânicos de baixo peso molecular, quelatando o ferro e transportando-olateralmentee em profundidade, tal como foi observado em regiões tropicais por Brasil (1960), Queiroz Neto \& Küpper (1965) e Boulet (1988a,b). A acumulação desse material ocorre pela preci pitação do ferro e seus compl exos formados com a matéria orgânica, quando do encontro com olençol de água. I sso pode ser notado pela formação de pequenas lamelas de crostas ferruginosas em zonas deflutuação do lençol, com acumulação posterior de material orgânico sobre essa camada ou mesmo concomitantemente.

Em síntese, do conjunto das observações efetuadas, é possível salientar:

1- As formações marinhas arenosas antecedem a sedimentação continental, criando condições para que esta ocorra numa depressão à retaguarda de um feixe derestinga, provavel menteo mais antigo.

2- A evolução pedológica do tipo Espodossolo (Podzol), com a formação de um horizonte Bhs, iniciou-se quando o nível do lençol freático encontrava-se mais baixo (regressão?) e, talvez, contemporâneo da formação do horizonte turfoso de paleovárzea brejosa (5Ob);

3- Posteriormente, houve o soterramento deste horizonte turfoso por nova sedimentação francoargilo-siltosa, com nova pausa que permite a formação de pequeno horizonte orgânico (3Ob);

4- Contemporaneamente ou pouco posterior, ocorreu a escavação de um canal fluvial, cujos sedimentos seixosos indicavam competência de transporte, portanto, energia mais el evada (torrencial?);

5- Finalmente, uma última sedimentação recobriu esses testemunhos, com a pausa atual que permite a evolução do horizonte A;

6- O estudo dos solos nas duas toposseqüências mostrou que os solos são importantes para a caracterização da evolução desse setor da planície costeira.

Alguns pontos restam a verificar na toposseqüência 2:

- com relação à continuidade do horizonte $\mathrm{Bh}$, o ponto 6 situa-se em um cordão arenoso pouco mais alto, sendo o nível desse Bh aproximadamente o mesmo do horizonte orgânico enterrado (3Ob). Entre o ponto 6 e o ponto 3, percebeu-se leve depressão com água aflorante, o que dificultou as observações pel otrado. Assim, a continuidadedesse horizonte indicado na figura ainda é hipotética, sendo necessário aprofundar as observações;

- o espaço de cerca de $15 \mathrm{~m}$ entre os pontos 4 e 5 , para precisar o contato entre os sedimentos marinhos e continentais e as eventuais relações entre os horizontes $\mathrm{Bh}$ e $5 \mathrm{Ob}$, bem como a configuração mais exata da bolsa de cascalho, da mesma forma que entre as tradagens 2 e 4;

- as idades absolutas, sobretudo com carbono 14, para situar no tempo os eventos e precisar melhor as relações entre os diferentes el ementos. 


\section{CONCLUSÕES}

1. A constituição geral da planície litorânea mostra seqüências de deposição arenosa marinha, sedimentos continentais e material orgânico, que imprimem desenvol vimentos pedológicos aparentemente independentes e indicam seqüências cronológicas de formação.

2. Os diferentes níveis de terraços marinhos encontrados, cordões recentes, terraços marinhos baixos e terraços marinhos altos, além de camadas contínuas e espessas de ortstein, a 4-5 m de profundidade, indicam evolução com podzolização intensa no passado. A formação do Espodossolo nos diferentes terraços não se inicia ao mesmo tempo, portanto, esses sol os indi cariam evol ução/desenvol vimento em diferentes momentos (sucessivos) de passado recente próximo, o que, possivelmente, coincide com os níveis de rebaixamento do mar durante o Holoceno.

3. As planícies de sedimentação continental, envolvendo setores entulhados com diversos níveis de horizontes enter rados demonstram deposição de pequena energia (material fino), ao passo que os setores preenchidos por níveis de cascal ho e seixos grosseiros evidenciam ter havido deposição de torrente ou no mínimo deforte energia detransporte, sendo indicadores de condições climáticas e pedológicas distintas das atuais. Paralelamente, a presença de horizontes turfosos entremeados na sedimentação franco-argilo-siltosa indica níveis anteriores ocupados pela planície aluvial e com tempo suficiente para formação de solos orgânicos.

4. A evolução pedológica do tipo Espodossolo (Podzol), com a formação de um horizonte Bhs, iniciou-sequando onível dolençol freático encontravase mais baixo (regressão marinha), o que propiciou a preci pitação dos compostos humo-férricos.

\section{LITERATURA CITADA}

BOULET, R. Análise estrutural da cobertura pedológica e a experimentação agronômica. In: CONGRESSO BRASILEIRO DE CIÊNCIA DO SOLO, 21., Campinas, 1987. Anais. Campinas, Sociedade Brasileira de Ciência do Solo, 1988a. p.431-446.
BOULET, R Análise estrutural da cobertura pedológica e cartografia. In: CONGRESSO BRASI LEIRO DE CIÊNCIA DO SOLO, 21., Campinas, 1987. Anais. Campinas, Sociedade Brasileira de Ciência do Solo, 1988b. p.79-90.

BRASIL - Ministério da Agricultura. Levantamento de Reconhecimento dos Solos do Estado de São Paulo. Rio de J aneiro, Serviço Nacional de Pesquisa Agropecuária, 1960. 634p. (Boletim 12).

CAMARGO, O.A.; MONIZ, A.C.; J ORGE, J .A. \& VALADARES, J .M.A.S. Métodos de análise química, mineralógica e física de solos do Instituto Agronômico de Campinas. Instituto Agronômico de Campinas, 1986. 94p. (Boletim Técnico, 106)

CAMARGO, M.N.; KLANT, E. \& KAUFFMAN, J .H. Classificação de solos usada em levantamentos no Brasil. B. Inf. SBCS, 12:11-33, 1987.

EMPRESA BRASILEIRA DE PESQUISA AGROPECUÁRIA EMBRAPA. Centro Nacional de Pesquisa de Solos. Sistema brasileiro de classificação de solos. Brasilia, 1999. 412p.

LEMOS, R.C. \& SANTOS, R.D. Manual de descrição e col eta de solo no campo. 3.ed. Campinas, Sociedade Brasileira de Ciência do Solo, 1996. 83p.

OLIVEIRA, J .B.; CAMARGO, M.N.; ROSSI, M. \& CALDERANO FILHO, B. Mapa pedológico do estado de São Paulo: legenda expandida. Campinas, I nstituto Agronômico. RiodeJ aneiro, EMBRAPA-Solos. Campinas, 1999. 64p.

QUEIROZNETO, J.P.\& KÜPPER, A. Os solos. In: A BAIXADA Santista. Aspectos geográficos. As bases físicas. São Paulo, Universidade de São Paulo, 1965. p.67-92.

RADAMBRASIL. Ministério de Minas e Energia. Levantamento dos Recursos Naturais - Folhas SF 23/24, Rio de J aneiro/ Vitória, 32:780. 1983.

ROSSI, M. \& QUEIROZ NETO, J .P. Amostras circulares de rede de drenagem para o estudo de solos de regiões tropicais umidas escarpadas e litorâneas. São Paulo, Brasil. In: CONGRESSO LATINO-AMERICANO DE CIÊNCIA DO SOLO, 13., Águas deLindóia, 1996. Águas de Lindóia, 1996. (CD Rom)

ROSSI, M. \& QUEIROZ NETO, J .P. Ensaio Morfopedológico em Escarpa Tropical Úmida: Serra do Mar - SP. In: SIMPÓSIO NACIONAL DE GEOMORFOLOGIA. SOCIEDADE \& NATUREZA, Revista do Departamento de Geografia. Universidade Federal de Uberlândia/E dição Especial Uberlândia, MG. Resumo expandido. Uberlândia, 1996b. p.457-461. 